\title{
Oral myiasis: A case report in a child with cerebral palsy
}

\author{
Ana Margarida Melo Nunes ${ }^{1}$, Wellington José Alves Nunes ${ }^{2}$, Cecilia Claudia Costa Ribeiro ${ }^{1}$, Fernanda Fe- \\ rreira Lopes ${ }^{1}$, Claudia Maria Coelho Alves ${ }^{1}$ \\ ${ }^{1}$ Federal University of Maranhão. \\ ${ }^{2}$ Hospital Infantil Dr. Juvêncio Mattos.
}

Correspondence:

Sírios Street, $n^{\circ} 86$, Portal dos Vinhais

São Luis-Ma-Brasil , 65000.000

Email: cacaucoelho@bol.com.br

Received: $23 / 06 / 2010$

Accepted: 12/07/2010

\author{
Melo Nunes AM, Alves Nunes WJ, Costa Ribeiro CC, Ferreira Lopes F, \\ J Clin Exp Dent. 2010;2(3):e157-9. \\ http://www.medicinaoral.com/odo/volumenes/v2i3/jcedv2i3p157.pdf \\ Article Number: 50337 http://www.medicinaoral.com/odo/indice.htm \\ (C) Medicina Oral S. L. C.I.F. B 96689336 - eISSN: 1989-5488 \\ eMail: jced@jced.es
} Coelho Alves M. Oral myiasis: A case report in a child with cerebral palsy.

\begin{abstract}
This case report added Myiasis is a parasitic disease that affects humans and other vertebrates. A rare condition in humans, myiasis is a worldwide phenomenon, with a higher incidence being observed in tropical and subtropical regions. Oral myiasis is rarely observed in children, is uncommon in the oral cavity, more specifically periodontal tissue. This uncommon condition is more prevalent in tropical and subtropical American and others country where low socioeconomic conditions, residence in rural areas, mental deficiency and precarious hygiene conditions. This case reports a reality of a child with cerebral palsy in a Public Hospital in São Luis, Ma, Brasil.
\end{abstract}

Key words: myiasis, cerebral palsy, periodontal. 


\section{Introduction}

Myiasis is a parasitic disease that affects humans and other vertebrates. The disease is caused by dipteran larvae that may complete their life cycle inside the host body, feeding on dead or living tissues (1). Although a rare condition in humans, myiasis is a worldwide phenomenon, with a higher incidence being observed in tropical and subtropical regions of Africa and America due to the predominance of favorable climatic conditions of heat and humidity $(2,3)$. Clinical manifestations depend on the tissue involved and the larval population is directly proportional to the number of eggs deposited and the period of time that elapsed between infestation and diagnosis and treatment of the disease. In humans, the sites most commonly affected are the skin, nose, ear, eyes, anus, vagina, and mouth. Oral myiasis is rarely observed in healthy humans $(3,4)$ his infection is uncommon in the oral cavity, more specifically periodontal tissue $(5,6)$. Risk factors for the acquisition of this parasitosis include low socioeconomic conditions, residence in developing countries and rural areas, mental deficiency and poor hygiene conditions $(1,3,6-8)$

In view of the interest of dental professionals in myiasis, we report here a rare case of myiasis involving periodontal tissue in a patient with cerebral palsy.

\section{Case report}

A 2-year-old girl with cerebral palsy from a rural area in the State of Maranhão, Brazil, and of low socioeconomic status was hospitalized at Hospital Infantil Dr. Juvêncio Mattos with signs and symptoms of malnutrition, pneumonia and generalized edema.

Evaluation by a dental surgeon was requested since the mother reported the observation of a larva entering and leaving the gingiva of her daughter. Anamnesis revealed that at home the patient was always lying in her bed with the mouth half-open and not reacting to external stimu-

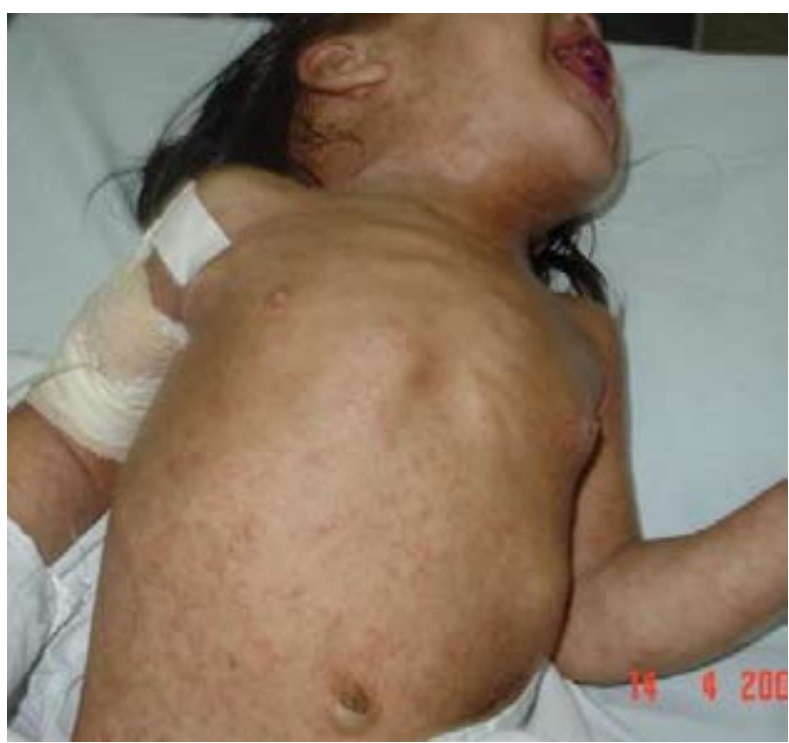

Fig. 1. Patient showing clinical signs of scabies. li. Physical examination showed that the patient breathed through the mouth and that her body was covered with scabies (Figure 1). Intraoral examination showed an ogival palate and deficient oral hygiene but no caries lesions. In addition, edema enlarging the region of the palate from the primary maxillary left first molar to the primary maxillary left lateral incisor was observed (Figure 2). Drainage of a sanguinolent exudate was noted upon palpation.

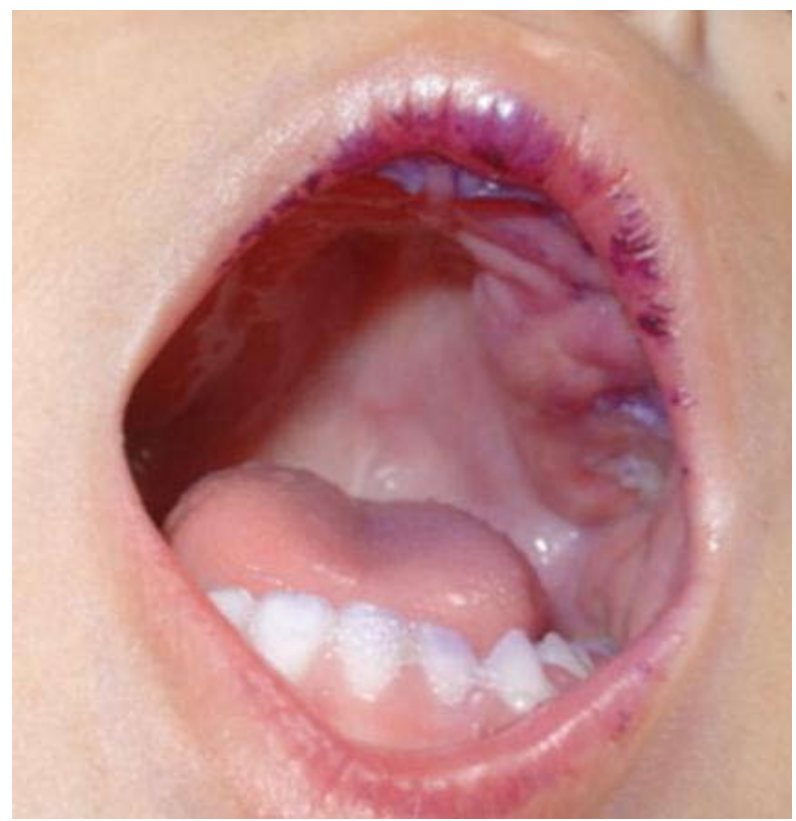

Fig. 2. Edema in the region of the palate.

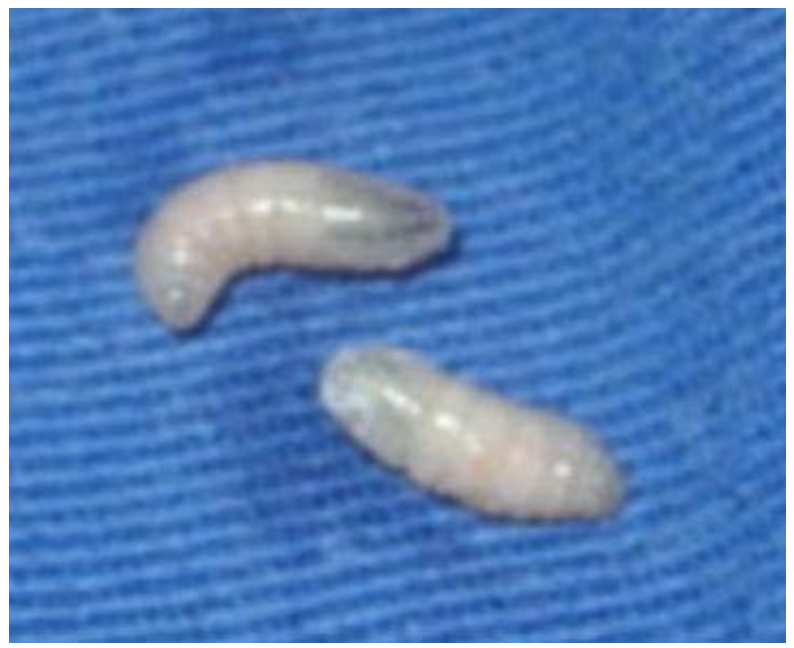

Fig. 3. Larvae found in the patient.

In view of acute symptoms of anemia (hematocrit: $26 \%$, hemoglobin: $8.5 \mathrm{mg} / \mathrm{dL}$ ), the patient was referred to a surgical center for treatment under inhalation anesthesia, in agreement with the anesthetist. Exploration of the palatal region revealed deepening of the gingival sulcus, with formation of a periodontal pocket in the region of the primary maxillary left first molar and primary maxillary left canine (Figure 3), and two larvae measuring 
approximately $1 \mathrm{~cm}$ in length were removed by curettage (Figures 4 and 5). After drainage of the exudate, the surgical wound was cleaned by irrigation with saline solution. Since the patient was receiving parenteral cephalothin and amikacin for the treatment of pneumonia, no additional medication was prescribed and the girl remained under the care of the pediatrics team of the hospital. The postoperative evolution of the patient was favorable, with regression of the palatal edema $72 \mathrm{~h}$ after the dental procedure. However, the patient developed septicemia which resulted in her death 25 days after the dental procedure.

\section{Discussion}

Oral myiasis is a rare condition observed in growing children and in healthy adults; however, this infection has frequently been reported in patients with mental deficiencies (5,7-9). In addition, alcoholism, senility, hemiplegia and an open mouth during sleep may facilitate the development of oral myiasis (5). The diagnosis of myiasis is usually made by the observation of larval movement; however, a more accurate diagnosis is necessary when the larva is located under the skin (9). In some cases, the clinical presentation of the lesion may lead to the erroneous diagnosis of minor salivary gland adenoma (10). Although the disease can affect children, few cases of oral myiasis in children below the age of 3 have been reported in the literature (3). These patients are completely dependent on their caregivers; however, in situations of low socioeconomic level these caregivers tend to neglect the oral hygiene of the patients because of the lack of health education (11).

Individuals living in rural areas are in closer contact with dipteran flies, a fact favoring contamination. According to Rossi-Schneider et al. (2007) (8), control of the fly population is a sanitary measure that should be adopted to reduce the occurrence of myiasis in humans.

Among the cases of oral myiasis reported in the literature, only one involves the posterior region of the oral cavity, a fact emphasizing the uncommon location of the larvae in the present case, more specifically between the mesial root of primary maxillary left first molar and primary maxillary left canine. The detection of two larvae in the lesion agrees with the findings that, in children, the larval population is always small (3). Although the case described by Bar Droma et al. (2007) (3) involved the posterior region, a fact supporting contaminated foods as a possible route of transmission at this site, in the present case direct inoculation was probably the route of transmission since the domiciliary situation of the patient (permanently lying in her bed with the mouth halfopen) favored the deposition of eggs and larval development. Similar findings have been reported by Gunbay et al. (1995) (4). The eggs are deposited on the gingival surface and transported to the gingival sulcus where they find the ideal environment for development, causing inflammation and destruction of adjacent tissues.

Recently, ivermectin, a semi-synthetic macrolide antibiotic used in veterinary medicine, has been applied to the treatment of oral myiasis. This medication activates the release of gamma-aminobutyric acid which induces the death of the larvae and their spontaneous elimination $(7,9)$.

In view of the systemic conditions of the present patient, complete removal of the larvae and abundant irrigation with saline solution were adopted as treatment (6) without administration of additional medication since the patient was treated for severe anemia and pneumonia and already received medication. This decision was made in agreement with the medical support team.

The present case and its consequences show that educational measures, basic sanitation and medical care close to home should be implemented especially in developing countries to improve the quality of life of their populations.

\section{References}

1. Gursel M, Aldemir OS, Ozgur Z, Ataoglu T. A rare case of gingival myiasis caused by Diptera ( Calliphoridae). J Clin Periodontol 2002;29:777-80

2. Meinking TL, Burkhart CN, Burkhart CG. Changing paradigms in parasitic infections: common dermatological helminthic infections and cutaneous myiasis. Clin Dermatol 2003;21:407-16.

3. Droma EB, Wilamowski A, Schnur H, Yarom N, Scheuer E, Schwartz E. Oral myiasis: a case report and literature review. Oral Surg Oral Med Oral Pathol Oral Radiol Endod 2007;103:92-6.

4. Günbay S, Biçakçi N, Canda T, Canda S. A case of myiasis gingiva. J Periodontol 1995;66:892-5.

5. Anil S, Jacob OA, Harri S. Oral myiasis: a case report. Ann Dent. 1989;48:28-30.

6.Gomez RS, Perdigão PF, Pimenta FJ, Rios Leite AC, Tanos de Lacerda JC, Custódio Neto AL. Oral myiasis by screwworm Cochliomyia hominivorax. BR J Oral Maxillofac Surg. 2003;41:115-6

7. Shinohara EH, Martini MZ, Oliveira Neto HG, Takahashi A. Oral myiasis treated with ivermectin: case report. Braz Dent J 2004;15:7981

8. Rossi-Schneider T, Cherubini K, Yurgel LS, Salum F, Figueiredo MA. Oral myiasis: a case report. J Oral Sci 2007;49:85-8.

9. Carvalho RW, Santos TS, Antunes AA, Laureano Filho JR, Anjos ED, Catunda RB. Oral and maxillofacial myiasis associated with epidermoid carcinoma: a case report. J Oral Sci 2008;50:103-5. Erratum in: J Oral Sci 2008;50:237

10. Kamboj M, Mahajan S, Boaz K.Oral myiasis misinterpreted as salivary gland adenoma. J Clin Pathol 2007;60:848.

11. Abdo EN, Sette-Dias AC, Comunian CR, Dutra CE, Aguiar EG. Oral myiasis: a case report. Med Oral Patol Oral Cir Bucal 2006;11:E130-1. 